\title{
Gender-Specific Incidence and Predictors of Cognitive Impairment among Older Koreans: Findings from a 6-Year Prospective Cohort Study
}

\author{
Jiyoung Lyu' and Hae-Young Kim² ${ }^{\otimes}$ \\ ${ }^{1}$ National Institute of Dementia, Seongnam, Republic of Korea \\ ${ }^{2}$ Department of Health Policy and Management, College of Health Sciences \& Department of Public Health Sciences, Graduate School, \\ Korea University, Seoul, Republic of Korea
}

Objective This study investigated gender-specific incidence and predictors of cognitive impairment among community-dwelling older adults in South Korea.

Methods Using data from the 2006 and 2012 Korean Longitudinal Study of Ageing (KLoSA), 925 females and 834 males aged 65 and over without cognitive impairment at 2006 were analyzed separately. Cognitive impairment was measured based on the Korean version of the Mini-Mental State Exam (K-MMSE) normative score. Generalized Estimating Equations (GEE) was conducted to examine the predictors of cognitive impairment at 6-year follow up.

Results Incidence of cognitive impairment at 2012 was significantly higher for women (30.5\%) than men (26.1\%). GEE result showed that depression was significantly associated with cognitive impairment for both genders (female: $\mathrm{OR}=2.26,95 \% \mathrm{CI}=1.63-3.12$; male: $\mathrm{OR}=3.26,95 \% \mathrm{CI}=2.19-4.83)$. Having IADL limitations $(\mathrm{OR}=1.15,95 \% \mathrm{CI}=1.03-1.28)$, high blood pressure $(\mathrm{OR}=1.72,95 \% \mathrm{CI}=1.27-$ $2.34)$, poor hearing $(\mathrm{OR}=1.94,95 \% \mathrm{CI}=1.29-2.92)$, regular exercise $(\mathrm{OR}=0.67,95 \% \mathrm{CI}=0.45-0.99)$, and normal weight $(\mathrm{OR}=1.39,95 \%$ $\mathrm{CI}=1.03-1.86)$ were significant predictors of cognitive impairment only among women. In contrast, age $(\mathrm{OR}=1.04,95 \% \mathrm{CI}=1.01-1.07)$ and $\mathrm{ADL}$ limitations $(\mathrm{OR}=1.48,95 \% \mathrm{CI}=1.21-1.82)$ were significant predictors of cognitive impairment at follow-up only among men.

Conclusion Findings of this study show gender-specific predictors of cognitive impairment among older Koreans. This study can provide information for clinicians and policy makers to develop different intervention strategies considering gender differences in the progress of cognitive impairment.

Psychiatry Investig 2016;13(5):473-479

Key Words Cognition, Risk factors, Sex differences, Longitudinal studies, Elderly.

\section{INTRODUCTION}

With a rapid growth in the older population, geriatric health problems become important concerns worldwide. Cognitive impairment is a major geriatric health problem among older adults because cognitive decline increases with age. Although cognitive decline is a normal aging process, many people concern about cognitive impairment because people with mild cognitive impairment have a high risk of eventually progress-

Received: July 1, 2015 Revised: October 16, 2015

Accepted: December 28, 2015 Available online: June 1, 2016

$\triangle$ Correspondence: Hae-Young Kim, DDS, PhD

Department of Health Policy and Management, College of Health Sciences, Korea University, 145 Anam-ro, Seongbuk-gu, Seoul 02841, Republic of Korea Tel: +82-2-3290-5667, Fax: +82-2-940-2879, E-mail: kimhaey@korea.ac.kr

(c) This is an Open Access article distributed under the terms of the Creative Commons Attribution Non-Commercial License (http://creativecommons.org/licenses/by$\mathrm{nc} / 3.0$ ) which permits unrestricted non-commercial use, distribution, and reproduction in any medium, provided the original work is properly cited. ing to Alzheimer's disease. ${ }^{1}$ According to the Korea Ministry of Health and Welfare, ${ }^{2}$ about 0.5 million older Koreans suffered from dementia in 2012, and the number of older Koreans suffering from dementia is expected to increase up to 2.7 million by 2050. Since dementia is a risk factor for mortality ${ }^{3}$ and involves high health care costs, ${ }^{4}$ it is not surprising that there is a growing interest in cognitive health.

In Korea, cognitive impairment and dementia are more prevalent among women than men. ${ }^{5,6}$ The number of older adults aged 65 and over diagnosed with dementia in 2012 was about 0.16 million for men and 0.38 million for women, respectively. ${ }^{2}$ Since women outlive men, this statistics may not be surprising. However, many studies reported that being a woman is a risk factor for cognitive impairment. ${ }^{7}$ Gender differences in work and family roles may explain mental health disparities by gender. ${ }^{8}$ Since women have lower education, lower wages, and less social benefits than men, disadvantages 
in socioeconomic structure could lead to gender differences in the prevalence of cognitive impairment.

Previous studies have identified several socio-demographic factors, health factors, and health behaviors as predictors of variability in cognition in later life. Among the socio-demographic factors, older age, ${ }^{9}$ not cohabiting with a partner, ${ }^{10}$ lower education, ${ }^{11}$ lower income, ${ }^{9}$ and living in a rural area ${ }^{12}$ were associated with poor cognitive functioning. In terms of health factors, having poor self-rated health, ${ }^{13}$ having ADL or IADL limitations, ${ }^{9}$ having chronic illnesses, ${ }^{14}$ being sensory impaired, ${ }^{15}$ and being depressed ${ }^{16}$ were all risk factors for declines in cognitive functioning. Health behaviors have also been taken into account. Current smokers reported poor cognitive functioning, ${ }^{17}$ while normal drinkers, ${ }^{18}$ people who regularly exercise ${ }^{19}$ people with normal weight, ${ }^{9}$ and people who participate in social activities ${ }^{20}$ reported good cognitive functioning.

When the magnitude of gender differences regarding above health characteristics determinants were taken into account, structural and psychosocial factors were more important for women, while behavioral factors were more important for men. ${ }^{21}$ Therefore, predictors of cognitive impairment may be different by gender. However, studies identifying gender-specific risk factors for cognitive impairment are rare, and if gender-specific models were examined, most studies were conducted in a cross-sectional design. ${ }^{7,22}$ Since longitudinal studies examining predictors of cognitive impairment are few, it is not clear which gender-specific factors have causal relationships with cognitive impairment. Therefore, this study attempts to fill this gap and examine the gender-specific incidence and predictors of cognitive impairment, using a nationally representative sample of older Koreans from 2006 to 2012.

\section{METHODS}

\section{Study sample}

Data for this study came from the 2006 and 2012 waves of the Korean Longitudinal Study of Ageing (KLoSA), a nationally representative longitudinal survey including community-dwelling middle and old-aged population who are aged 45 and over. The sampling framework was based on the probability proportional to size (PPS) systematic sampling of the 2005 Korean Census and Housing Enumeration Districts (ED), stratified by 15 metropolitan areas and provinces, urban/rural regions, and apartment building/non-apartment dwelling. Age-eligible households were selected within each ED. Using a multistage stratified probability sampling based on geographical areas, respondents in individual households were interviewed using computer assisted personal interviewing (CAPI) methods. The KLoSA survey includes questionnaires on demographics, family, health, employment, income, assets, and subjective expectations and satisfaction. ${ }^{23}$ The first KLoSA survey was conducted in 2006, with 10,254 respondents among 6,171 households. In 2008, 8,688 respondents were followed-up. In the 2010 third wave, 7,920 respondents were followed-up. The fourth wave in 2012 comprised 7,486 respondents, representing $73.0 \%$ of the original panel.

In this study, the sample was restricted to older adults aged 65 and over at baseline who completed both 2006 and 2012 interviews, and were not cognitively impaired at baseline. Cognitive impairment was defined based on the cut-off scores (2 standard deviation of the mean) from the K-MMSE normative data (see also Measures section). Among 7,486 respondents who completed both 2006 and 2012 interviews, 4,686 respondents under age 65 were excluded. Among 2,800 respondents who met the age criteria, 805 respondents who were cognitively impaired at baseline were excluded from the sample. Among 1,995 respondents who met sample criteria, a pool of 1,759 subjects remained eligible for empirical analysis after listwise deletion of cases with missing values. The sample was subdivided into female and male groups, which consisted of 925 and 834 subjects, respectively.

\section{Measures}

\section{Cognitive impairment}

The measure of cognitive impairment was assessed with the Korean version of the Mini-Mental State Examination (KMMSE) that had a maximum score of 30 points. ${ }^{24}$ Both validity and reliability of K-MMSE instrument were established (Cronbach's alpha: 0.880). ${ }^{24} \mathrm{~K}-\mathrm{MMSE}$ is widely used for screening of cognitive impairment among older adults, ${ }^{24}$ and the normative data for K-MMSE has been developed for clinical use. ${ }^{25}$ Based on age, gender, and educational strata, the cutoff scores (2 standard deviation of the mean) from the KMMSE normative data were used to determine cognitive impairment. ${ }^{25}$ In this study, cognitive impairment measured at baseline was used for sample criteria, and cognitive impairment measured at follow-up was used as a dependent variable. Cognitive function (K-MMSE score) at baseline was also used as a covariate to predict cognitive impairment at follow-up.

\section{Socio-demographic factors}

In this study, age (in years), marital status ( $1=$ married, $0=$ others), a set of dichotomous variables of education (less than middle school (reference group), middle school graduate, high school graduate, and some college or more), household income (in quartiles), and region (1=living in a major city, $0=$ others) were included as pre-existing socio-demographic factors. Household income was measured from the 
imputed dataset. ${ }^{26}$ All socio-demographic factors were measured at baseline.

\section{Health factors}

Self-rated health was assessed with a 5-point likert scale, then dichotomized ( 1 =fair/poor health, $0=$ good/very good/ excellent health). Functional difficulty was measured with the number of Activities of Daily Living (ADL) and Instrumental Activities of Daily Living (IADL) limitations. ${ }^{27} \mathrm{ADL}$ items included having difficulty in dressing, washing face and hands, bathing, eating, transfer, toileting, and continence. ${ }^{28}$ IADL items included having difficulty in decorating, housework, preparing meals, laundry, outgoing for a short distance, using transportation, shopping, handling money, using telephone, and taking medicine. ${ }^{29}$ Each ADL and IADL item was dichotomized ( $1=$ need any help, $0=$ otherwise), then the sum scores of ADLs and IADLs were constructed. ADLs ranged from 0 to 7 , and IADLs ranged from 0 to 10 . Both validity and reliability of ADL and IADL instruments were established (Cronbach's alpha: 0.949 for ADL and 0.938 for IADL). ${ }^{28,29}$ Several physician-diagnosed chronic conditions (high blood pressure, diabetes, lung disease, liver disease, heart disease, and cerebrovascular disease) were measured, and each chronic condition was dichotomized ( $1=$ ever been diagnosed by a doctor, $0=$ otherwise). Based on the self-reported status of eyesight and hearing, poor eyesight was dichotomized (1=having fair/poor eyesight, $0=$ otherwise). Similarly, poor hearing was dichotomized ( 1 =having fair/poor hearing, $0=$ otherwise). Depression was measured by using Korean version of the short-form (10-item) Center for Epidemiological Studies Depression (CES-D) scale. ${ }^{30,31}$ Both validity and reliability of CES-D instrument were established ${ }^{30}$ (Cronbach's alpha: 0.796). The respondents were asked whether they had depressive symptoms during the past week. Each item was coded as 1 if the respondent had depressive symptoms more than three days. Two positive items were coded reversely. Respondents with more than 4 depressive symptoms were considered as being depressed. ${ }^{31,32}$ All health factors were measured at baseline.

\section{Health behaviors}

Smoking status was dichotomized ( $1=$ current smoking, $0=$ otherwise). Drinking status was dichotomized based on the respondents' drinking behavior $(1=$ normal drinking, $0=$ otherwise) ${ }^{18}$ In the KLoSA, the CAGE questions (cutting down, annoyance by criticism, guilty feeling, and eye-openers) were used to identify the respondent's drinking behavior. If the current drinker answered "yes" to one or none of the four CAGE questions, the respondent was considered to have normal drinking behavior. ${ }^{33}$ Physical activity was dichotomized (1= regular exercise, $0=$ otherwise). Body mass index (BMI) was dichotomized ( $1=$ normal weight, $0=$ otherwise) based on the definition from World Health Organization. ${ }^{34}$ Number of social participation ranged from 0 to 7 , including attending religious meeting, social clubs, leisure group, alumni society, volunteer groups, political party, and others. All health behaviors were measured at baseline.

\section{Statistical analysis}

In this study, analyses were conducted separately for females and males. For the descriptive analyses, means (M) and standard deviation (SD) were used to assess the sample characteristics. t-tests and chi-square tests were conducted to evaluate the gender differences in descriptive statistics. Then the generalized estimating equations model (GEE) was used to investigate predictors of cognitive impairment, accounting for autocorrelation issue. Due to the complexity of sampling design, all statistical analyses were conducted based on the weighted data using SPSS version 19 (IBM SPSS Inc., Chicago, IL, USA).

\section{RESULTS}

\section{Descriptive statistics}

Table 1 contains descriptive statistics for the study sample. The incidence of cognitive impairment at 2012 was higher among women than men (female: $30.5 \%$, male: $26.1 \%$; $\mathrm{p}=0.010$ ). In comparison, $35.0 \%$ of women and $20.0 \%$ of men were cognitively impaired at baseline. About $53.5 \%$ of women were married, while $92.5 \%$ of men were married. Compared to women, men were more educated, had higher household income, had better self-rated health, had less high blood pressure, had more lung disease, had less poor eyesight, were less depressed, and were more engaged in health behaviors.

\section{Generalized estimating equations result}

Table 2 contains the empirical result of a generalized estimating equations (GEE) model that describes predictors of cognitive impairment at follow-up. For both gender groups, depression was a significant predictor of cognitive impairment at follow-up controlling for other covariates (female: $\mathrm{OR}=2.26$, $\mathrm{p}<0.001$; male: $\mathrm{OR}=3.26, \mathrm{p}<0.001)$. Among women, having IADL limitations $(\mathrm{OR}=1.15, \mathrm{p}=0.015)$, high blood pressure $(\mathrm{OR}=1.72, \mathrm{p}<0.001)$, poor hearing $(\mathrm{OR}=1.94, \mathrm{p}=0.001)$, regular exercise $(\mathrm{OR}=0.67, \mathrm{p}=0.042)$, and normal weight $(\mathrm{OR}=1.39$, $\mathrm{p}=0.030$ ) were significantly associated with cognitive impairment at follow-up. In contrast, age $(\mathrm{OR}=1.04, \mathrm{p}=0.023)$ and $\mathrm{ADL}$ limitations $(\mathrm{OR}=1.48, \mathrm{p}<0.001)$ were significant predictors of cognitive impairment at follow-up only among men. 


\section{DISCUSSION}

This study was designed to examine the gender-specific incidence and predictors of cognitive impairment among older adults in Korea. Women had significantly higher incidence of cognitive impairment than men. Corresponding to previous studies, depression was a strong predictor for cognitive impairment in both female and male groups. ${ }^{16}$ However, several risk factors had different impacts on cognitive impairment by gender. Among women, IADL limitations, high blood pressure, poor hearing, regular exercise, and normal weight were significantly associated with cognitive impairment. In contrast, age and ADL limitations were significantly associated with cognitive impairment only among men.

In this study, several factors were unique predictors of cognitive impairment only among women. First, more IADL limitation was significantly associated with cognitive impairment. Since some of the IADL functions (housework, shop-

Table 1. Sample Characteristics at Baseline (2006)

\begin{tabular}{|c|c|c|c|c|c|c|c|}
\hline & \multicolumn{2}{|c|}{ Total $(\mathrm{N}=1,759)$} & \multicolumn{2}{|c|}{ Female $(\mathrm{N}=925)$} & \multicolumn{2}{|c|}{ Male $(\mathrm{N}=834)$} & \multirow{2}{*}{$\mathrm{p}$-value } \\
\hline & Mean (\%) & SD & Mean (\%) & SD & Mean (\%) & SD & \\
\hline \multicolumn{8}{|l|}{ Dependent variable } \\
\hline Cognitively impaired at $2012^{*}$ & 28.5 & & 30.5 & & 26.1 & & 0.010 \\
\hline \multicolumn{8}{|l|}{ Socio-demographic factors } \\
\hline Age (65-91) & 71.1 & 4.89 & 71.2 & 4.99 & 71.0 & 4.77 & 0.496 \\
\hline Married & 71.4 & & 53.5 & & 92.5 & & $<0.001$ \\
\hline Educational attainment & & & & & & & $<0.001$ \\
\hline Less than middle school & 67.2 & & 83.7 & & 47.7 & & \\
\hline Middle school graduate & 10.5 & & 7.3 & & 14.2 & & \\
\hline High school graduate & 15.2 & & 7.4 & & 24.5 & & \\
\hline Some college or more & 7.1 & & 1.6 & & 13.6 & & \\
\hline Household incomet (median) & 864.0 & & 719.0 & & 1087.0 & & $<0.001$ \\
\hline Living in a major city & 37.4 & & 36.0 & & 39.0 & & 0.700 \\
\hline \multicolumn{8}{|l|}{ Health factors } \\
\hline Fair/poor health & 39.0 & & 49.2 & & 27.0 & & $<0.001$ \\
\hline Number of ADL & 0.1 & 0.40 & 0.1 & 0.38 & 0.1 & 0.43 & 0.324 \\
\hline Number of IADL & 0.4 & 1.19 & 0.4 & 1.20 & 0.4 & 1.17 & 0.576 \\
\hline High blood pressure & 39.6 & & 42.8 & & 35.8 & & 0.002 \\
\hline Diabetes & 14.4 & & 15.5 & & 13.1 & & 0.162 \\
\hline Lung disease & 3.1 & & 1.8 & & 4.7 & & 0.001 \\
\hline Liver disease & 1.5 & & 0.9 & & 2.3 & & 0.019 \\
\hline Heart disease & 7.8 & & 7.9 & & 7.6 & & 0.701 \\
\hline Cerebrovascular disease & 3.2 & & 2.5 & & 4.0 & & 0.061 \\
\hline Poor eyesight & 31.3 & & 34.8 & & 27.0 & & $<0.001$ \\
\hline Poor hearing & 10.8 & & 9.2 & & 12.7 & & 0.012 \\
\hline Depression & 37.7 & & 45.0 & & 29.1 & & $<0.001$ \\
\hline Cognition score at $2006^{\ddagger}$ & 25.3 & 3.11 & 24.3 & 3.42 & 26.5 & 2.16 & $<0.001$ \\
\hline \multicolumn{8}{|l|}{ Health behaviors } \\
\hline Current smoking & 15.3 & & 3.7 & & 29.0 & & $<0.001$ \\
\hline Normal drinking & 25.2 & & 10.8 & & 42.1 & & $<0.001$ \\
\hline Regular exercise & 36.8 & & 31.0 & & 43.7 & & $<0.001$ \\
\hline Normal weight & 43.8 & & 41.3 & & 46.7 & & 0.035 \\
\hline Number of social participation & 0.9 & 0.85 & 0.8 & 0.76 & 1.1 & 0.93 & $<0.001$ \\
\hline
\end{tabular}

*cognition score at 2012 (mean: 21.8, SD: 7.46 for total/mean: 21.0, SD: 7.20 for female/mean: 22.7, SD: 7.65 for male), ${ }^{\dagger}$ annual household income in 10,000 Korean won, $\neq$ cognitively impaired at 2006 (28.8\% for total/35.0\% for female/20.0\% for male). SD: standard deviation 
ping, and meal preparation) can be routine work for women, limitation on these functions may be more problematic for women. Therefore, the impact of IADL limitation on cognitive impairment may be apparent among women. Second, high blood pressure was found to be a risk factor for cognitive impairment among older women in Korea. Previous studies of- ten reported that high blood pressure is a risk factor for cognitive impairment. ${ }^{35}$ Moreover, studies showed that blood pressure levels increase in women after menopause. ${ }^{36}$ In other words, loss of estrogen with menopause may be related to the elevated blood pressure level among postmenopausal women. Differences in hemodynamic characteristics and hormonal pro-

Table 2. Generalized estimating equations result: predictors of cognitive impairment at follow-up

\begin{tabular}{|c|c|c|c|}
\hline & Total $(\mathrm{N}=1,759)$ & Female $(\mathrm{N}=925)$ & Male $(\mathrm{N}=834)$ \\
\hline & OR (95\% CI) & OR $(95 \% \mathrm{CI})$ & OR (95\% CI) \\
\hline \multicolumn{4}{|l|}{ Socio-demographic factors } \\
\hline Female & $1.00(0.73,1.36)$ & & \\
\hline Age & $1.03(1.01,1.06)^{* *}$ & $1.03(1.00,1.06)$ & $1.04(1.01,1.07)^{*}$ \\
\hline Married & $1.02(0.75,1.38)$ & $1.13(0.81,1.58)$ & $0.76(0.44,1.32)$ \\
\hline \multicolumn{4}{|c|}{ Education (ref: less than middle school) } \\
\hline Middle school graduate & $0.79(0.50,1.25)$ & $0.92(0.50,1.69)$ & $0.65(0.35,1.20)$ \\
\hline High school graduate & $0.97(0.65,1.44)$ & $1.07(0.54,2.12)$ & $1.00(0.63,1.58)$ \\
\hline Some college or more & $0.99(0.58,1.70)$ & $0.88(0.21,3.65)$ & $0.99(0.52,1.89)$ \\
\hline \multicolumn{4}{|c|}{ Household income (ref: 1st quartile) } \\
\hline 2nd quartile & $0.83(0.62,1.11)$ & $0.85(0.59,1.23)$ & $0.84(0.54,1.29)$ \\
\hline 3rd quartile & $0.98(0.69,1.39)$ & $1.16(0.75,1.80)$ & $0.92(0.56,1.51)$ \\
\hline 4th quartile & $0.89(0.62,1.28)$ & $0.93(0.60,1.45)$ & $1.00(0.58,1.73)$ \\
\hline Living in a major city & $0.92(0.72,1.18)$ & $0.81(0.59,1.10)$ & $1.17(0.83,1.66)$ \\
\hline \multicolumn{4}{|l|}{ Health factors } \\
\hline Fair/poor health & $0.88(0.67,1.17)$ & $0.75(0.54,1.06)$ & $1.02(0.66,1.58)$ \\
\hline Number of ADL & $1.31(1.13,1.51)^{* * *}$ & $1.18(0.96,1.43)$ & $1.48(1.21,1.82)^{* * *}$ \\
\hline Number of IADL & $1.12(1.03,1.21)^{* *}$ & $1.15(1.03,1.28)^{*}$ & $1.08(0.97,1.21)$ \\
\hline High blood pressure & $1.40(1.10,1.79)^{* *}$ & $1.72(1.27,2.34)^{* * *}$ & $1.13(0.79,1.62)$ \\
\hline Diabetes & $1.13(0.84,1.53)$ & $1.06(0.73,1.54)$ & $1.21(0.77,1.91)$ \\
\hline Lung disease & $1.48(0.89,2.45)$ & $1.12(0.40,3.15)$ & $1.58(0.89,2.78)$ \\
\hline Liver disease & $0.90(0.36,2.30)$ & $0.84(0.08,8.40)$ & $0.84(0.26,2.70)$ \\
\hline Heart disease & $0.72(0.46,1.14)$ & $0.68(0.39,1.21)$ & $0.70(0.36,1.37)$ \\
\hline Cerebrovascular disease & $1.27(0.76,2.13)$ & $0.93(0.31,2.82)$ & $1.38(0.80,2.38)$ \\
\hline Poor eyesight & $1.05(0.80,1.38)$ & $0.97(0.69,1.36)$ & $1.24(0.84,1.83)$ \\
\hline Poor hearing & $1.36(0.98,1.90)$ & $1.94(1.29,2.92)^{* *}$ & $0.87(0.54,1.39)$ \\
\hline Depression & $2.59(2.00,3.36)^{* * *}$ & $2.26(1.63,3.12)^{* * *}$ & $3.26(2.19,4.83)^{* * *}$ \\
\hline Cognition score at 2006 & $0.99(0.95,1.03)$ & $0.99(0.95,1.04)$ & $0.95(0.87,1.02)$ \\
\hline \multicolumn{4}{|l|}{ Health behaviors } \\
\hline Current smoking & $0.88(0.62,1.25)$ & $0.97(0.51,1.84)$ & $0.89(0.59,1.35)$ \\
\hline Normal drinking & $0.88(0.64,1.20)$ & $1.08(0.68,1.71)$ & $0.84(0.56,1.24)$ \\
\hline Regular exercise & $0.73(0.55,0.97)^{*}$ & $0.67(0.45,0.99)^{*}$ & $0.95(0.66,1.37)$ \\
\hline Normal weight & $1.36(1.08,1.73)^{*}$ & $1.39(1.03,1.86)^{*}$ & $1.15(0.81,1.63)$ \\
\hline Number of social participation & $1.01(0.86,1.18)$ & $1.06(0.86,1.32)$ & $0.90(0.74,1.10)$ \\
\hline \multicolumn{4}{|l|}{ Goodness of fit } \\
\hline QIC & 1864.1 & 1172.1 & 889.6 \\
\hline
\end{tabular}

${ }^{*} \mathrm{p}<.05,{ }^{* *} \mathrm{p}<.01,{ }^{* * *} \mathrm{p}<.001$. QIC: quasi likelihood under independence model criterion, ADL: activity of daily living, OR: odds ratio, CI: confidence interval, Ref: reference group 
files could explain why older women with high blood pressure were more likely to be cognitively impaired. ${ }^{36}$ Third, this study finding suggests that older women with poor hearing were more likely to be cognitively impaired. Since older adults with hearing impairments can have communication problems, ${ }^{37}$ their social network can become limited. In addition, psychosocial factors such as social ties and social support play more important role on cognitive health among women than among men. ${ }^{21}$ Therefore, poor hearing can be a significant risk factor for cognitive impairment among women. Fourth, regular exercise was found to be a protective factor for cognitive impairment. Women tend to have more vascular risk factors (ex. stress, abdominal obesity, high blood pressure, and high total cholesterol), and the beneficial effect of exercise on both dementia and vascular disease has been well reviewed. ${ }^{38}$ Therefore, exercise can be effective on cognitive health among women. Fifth, normal weight was found to be a risk factor for cognitive impairment among older women in Korea. Often, Korean women with normal weights have abdominal obesity, which is a serious risk factor for cognitive impairment. Since the effect of BMI on cognition is inconclusive, using different measures such as waist-hip ratio or waist circumference may explain this unexpected finding.

On the contrary, several risk factors for cognitive impairment were found only among men. First, age was a significant risk factor for cognitive impairment only among men. This is unexpected finding because age has been consistently found to be a strong risk factor for cognitive impairment for both genders. Among women in our study sample, age-related health changes between 6 years had significant impact on cognitive impairment. Therefore, the unique effect of age itself may have not been apparent. Second, more ADL limitation was significantly associated with cognitive impairment among men. In Korean culture, older men get more assistance when they have limitations in basic activities, which make them feel helpless. Since negative mood worsens cognitive activities, ${ }^{39}$ ADL limitations may accelerate cognitive impairment among Korean men.

There are some limitations in this study that should be noted. First, cognitive impairment was defined using a screening tool. Therefore, cognitive impairment prevalence may be higher than those actually diagnosed. Second, as with any secondary data analysis, several biological risk factors (e.g., APOE-e4 genotype, metabolic syndromes, etc.) could not be analyzed in this study. Since biological risk factors highly predict the cognitive impairment and dementia, ${ }^{40}$ clinical studies including these measures are recommended.

Although we had several limitations in our study, this study makes a number of important contributions. First, this study investigated the relationship between risk factors and cogni- tive impairment among Korean older adults using a nationally representative sample. Therefore, the findings from this study can be generalized. Second, this study examined gender differences, which could establish gender-specific strategies for the prevention and treatment of cognitive impairment among older adults in Korea. Third, this is a longitudinal study evaluating predictors of cognitive impairment in a 6-year period. Therefore, the results of this study can suggest causal relationships.

To conclude, this study holds significance as it investigated the gender-specific incidence and predictors of cognitive impairment among older Koreans using nationally representative sample. Development of cognitive impairment was greater in older women, and gender specific risk factors for cognitive impairment were observed among older Koreans. This study suggests that clinicians and policy makers may need to consider gender in the progression of cognitive impairment. Further study is needed to examine the detailed causal relations between each gender specific risk factor and cognitive impairment.

\section{Acknowledgments}

This work was supported by the Korea University Grant (K1509901).

\section{REFERENCES}

1. Alzheimer's Association. 2012 Alzheimer's disease facts and figures. Alzheimers Dement 2012;8:131-168.

2. Korea Ministry of Health and Welfare. Recent Increase of Elderly with Dementia in Korea. Seoul, Korea: Korea Ministry of Health and Welfare; 2013

3. Agüero-Torres H, Fratiglioni L, Winblad B. Natural history of Alzheimer's disease and other dementias: review of the literature in the light of the findings from the Kungsholmen Project. Int J Geriatr Psychiatry 1998;13:755-766.

4. Alzheimer's Disease International. World Alzheimer Report 2010: The Global Economic Impact of Dementia. London: Alzheimer's Disease International; 2010.

5. Kim KW, Park JH, Kim MH, Kim MD, Kim BJ, Kim SK, et al. A nationwide survey on the prevalence of dementia and mild cognitive impairment in South Korea. J Alzheimers Dis 2011;23:281-291.

6. Choi SJ, Jung SS, You YS, Shin BS, Kim JE, Yoon SW, et al. Prevalence of Alzheimer's dementia and its risk factors in community-dwelling elderly Koreans. Psychiatry Investig 2008;5:78-85.

7. Lyu J, Lee CM, Dugan E. Risk factors related to cognitive functioning: a cross-national comparison of U.S. and Korean older adults. Int J Aging Hum Dev 2014;79:81-101.

8. Simon RW. Gender, multiple roles, role meaning, and mental health. J Health Soc Behav 1995;36:182-194.

9. Herzog AR, Wallace RB. Measures of cognitive functioning in the AHEAD Study. J Gerontol B Psychol Sci Soc Sci 1997;52:37-48.

10. Håkansson K, Rovio S, Helkala E, Vilska A, Winblad B, Soininen H, et al. Association between mid-life marital status and cognitive function in later life: population based cohort study. BMJ 2009;339:b2462.

11. Christensen H, Hofer SM, Mackinnon AJ, Korten AE, Jorm AF, Henderson AS. Age is no kinder to the better educated: absence of an association investigated using latent growth techniques in a community sample. Psychol Med 2001;31:15-28.

12. Liang J, McCarthy JF, Jain A, Krause N, Bennett JM, Gu S. Socioeco- 
nomic gradient in old age mortality in Wuhan, China. J Gerontol B Psychol Sci Soc Sci 2000;55:S222-S233.

13. Zelinski EM, Crimmins E, Reynolds S, Seeman T. Do medical conditions affect cognition in older adults? Health Psychol 1998;17:504-512.

14. Spiro A 3rd, Brady CB. Integrating health into cognitive aging: toward a preventive cognitive neuroscience of aging. J Gerontol B Psychol Sci Soc Sci 2011;66(suppl 1):i17-i25.

15. Tay T, Wang JJ, Kifley A, Lindley R, Newall P, Mitchell P. Sensory and cognitive association in older persons: findings from an older Australian population. Gerontology 2006;52:386-394.

16. Bierman EJ, Comijs HC, Jonker C, Beekman AT. Effects of anxiety versus depression on cognition in later life. Am J Geriatr Psychiatry 2005;13:686-693.

17. Anstey KJ, von Sanden C, Salim A, O’Kearney R. Smoking as a risk factor for dementia and cognitive decline: a meta-analysis of prospective studies. Am J Epidemiol 2007;166:367-378.

18. Lyu J, Lee SH. Alcohol consumption and cognitive impairment among Korean older adults: does gender matter? Int Psychogeriatr 2014;26: 335-340.

19. Lytle ME, Vander Bilt J, Pandav RS, Dodge HH, Ganguli M. Exercise level and cognitive decline: the MoVIES project. Alzheimer Dis Assoc Disord 2004;18:57-64.

20. Hsu HC. Does social participation by the elderly reduce mortality and cognitive impairment? Aging Ment Health 2007;11:699-707.

21. Denton M, Prus S, Walters V. Gender differences in health: a Canadian study of the psychosocial, structural and behavioural determinants of health. Soc Sci Med 2004;58:2585-2600.

22. Sachdev PS, Lipnicki DM, Crawford J, Reppermund S, Kochan NA, Trollor JN, et al. Risk profiles for mild cognitive impairment vary by age and sex: the Sydney Memory and Ageing study. Am J Geriatr Psychiatry 2012;20:854-865.

23. Korea Labor Institute. About KLoSA: The Korean Longitudinal Study of Ageing. Seoul, Korea: Korea Labor Institute; 2010.

24. Kang Y, Na DL, Hahn S. A validity study on the Korean Mini-Mental State Examination (K-MMSE) in dementia patients. J Korean Neurol Assoc 1997;15:300-308.

25. Han C, Jo SA, Jo I, Kim E, Park MH, Kang Y. An adaptation of the Korean mini-mental state examination (K-MMSE) in elderly Koreans: demographic influence and population-based norms (the AGE study). Arch Gerontol Geriatr 2008;47:302-310.

26. Song J, Lee SY, Yoon C, Yoon R, Song K-H, Kim B, et al. Multiple Im- putation of Missing Values in KLoSA: Models for Income and Wealth Variables. Seoul, Korea: Korea Labor Institute; 2007.

27. Won C, Yang K, Rho Y, Kim S, Lee E, Yoon J, et al. The Development of Korean Activities of Daily Living(K-ADL) and Korean Instrumental Activities of Daily Living (K-IADL) Scale. J Korean Geriatr Soc 2002; 6:107-120.

28. Won C, Rho Y, Kim S, Cho B, Lee Y. The Validity and Reliability of Korean Activities of Daily Living (K-ADL) Scale. J Korean Geriatr Soc 2002;6:98-106.

29. Won C, Rho Y, Sun W, Lee Y. The Validity and Reliability of Korean Instrumental Activities of Daily Living (K-IADL) Scale. J Korean Geriatr Soc 2002;6:273-280.

30. Cho MJ, Kim KH. Use of the Center for Epidemiologic Studies Depression (CES-D) Scale in Korea. J Nerv Ment Dis 1998;186:304-310.

31. Irwin M, Artin KH, Oxman MN. Screening for depression in the older adult: criterion validity of the 10-item Center for Epidemiological Studies Depression Scale (CES-D). Arch Intern Med 1999;159:1701-1704.

32. Ko KD, Cho YT, Cho SI, Sung JH, Cho BL, Son KY, et al. Association of health risk behaviors with mental health among elderly Koreans. J Korean Geriatr Soc 2012;16:66-73.

33. Ewing JA. Detecting alcoholism. The CAGE questionnaire. JAMA 1984;252:1905-1907.

34. WHO. The Asia-Pacific Perspective: Redefining Obesity and its Treatment. Geneva, Switzerland: World Health Organization; 2000.

35. Goldstein FC, Levey AI, Steenland NK. High blood pressure and cognitive decline in mild cognitive impairment. J Am Geriatr Soc 2013;61: 67-73.

36. Ferrario CM, Jessup JA, Smith RD. Hemodynamic and hormonal patterns of untreated essential hypertension in men and women. Ther Adv Cardiovasc Dis 2013;7:293-305.

37. Garstecki DC, Erler SF. Older adult performance on the communication profile for the Hearing Impaired: gender difference. J Speech Lang Hear Res 1999;42:785-796.

38. Hogervorst E, Clifford A, Stock J, Xin X, Bandelow S. Exercise to prevent cognitive decline and Alzheimer's disease: for whom, when, what, and (most importantly) how much? J Alzheimers Dis Parkinsonism 2012;2:e117.

39. Chepenik LG, Cornew LA, Farah MJ. The influence of sad mood on cognition. Emotion 2007;7:802-811.

40. Azad NA, Al Bugami M, Loy-English I. Gender differences in dementia risk factors. Gend Med 2007;4:120-129. 